La cortedad de datos en 1996 referidos al equipamiento nos impide una evaluación de los cambios al llegar a 1999 que será ciertamente el punto de partida para las estimaciones venideras en este punto.

La conservación física sigue siendo razonablemente aceptable, mientras que la seguridad sigue teniendo que ver con la presencia o ausencia de archiveros. Aunque se hace constar afirmativamente, en más de un caso, que se hacen estudios de identificación y valoración, la falta de especificación de los mismos hace pensar que se han quedado en estudios de identificación para la descripción, que no para la selección con vistas a la eliminación.

Algo más, en estas consideraciones de carácter general. Ningún sitio web en 1996. En 1999, también escasos si nos referimos a los propios: La Línea de la Concepción, Andújar. Sin embargo la información de los archivos municipales empieza a incorporarse a los sitios webs de los ayuntamientos respectivos, como es el caso de Córdoba, o de las Diputaciones Provinciales, en el caso de provincias con Planes de archivos.

Es muy posible que algunos Ayuntamientos o algunos archiveros, al acercarse a esas dos bases de datos y recuperar los de su archivo, no se vean satisfechos con la imagen obtenida. Se me ocurre recurrir a un mensaje positivo que figuraba en el protector de pantalla de los ordenadores que, con las bases de datos aludidas, se ofrecía a los asistentes en el stand de la Consejería de Cultura con ocasión del XIV Congreso Internacional de Archivos:

\section{¿No te gusta la imagen de tu archivo?}

\section{Cámbiala! Tienes ocasión y obligación de hacerlo. La fecha será el 31 de diciembre de 2000.}

Antonia Heredia Herrera

Directora del Archivo General de Andalucía

\section{Notas}

I. HEREDIA HERRERA, A. El plan de organización y descripción de archivos municipales de Sevilla. Proyecto y resultados. Actas del II Encontro Nacional de arquivos municipais en Montemornovo, Lisboa, 1992. pp. 63-74.

2. REY DE LAS PEÑAS, R. Plan de ordenación de archivos municipales de la Excma. Diputación Provincial de Huelva. Actas del II Congreso Nacional de ANABAD. Boletín de ANABAD, XXV, n² 2-3, 1985, pp. 24I-244.

3. HEREDIA HERRERA, A., RAVINA MARTÍN, M. BÍBARA, bibliografía archivística andaluza (19782000), Sevilla, Consejería de Cultura, 2000.

4. CENSARA, es una base de datos que ha recogido la última actualización del Censo de archivos del Sistema andaluz (diciembre, 1999) y permitirá incorporar las sucesivas actualizaciones.

5. HEREDIA HERRERA, A. Censo del Sistema andaluz de archivos. Sevilla. Consejería de Cultura, Archivo General de Andalucía, 1997.

6. Cfr. Censo del Sistema andaluz ... pp. 10 y ss.

7. Al reproducir las estadísticas totales y por provincias hemos evitado aquí volver a insistir, quedándonos sólo con las cifras totales.

\title{
La restauración de las pinturas murales del Instituto Vicente Espinel de Málaga en CD-ROM
}

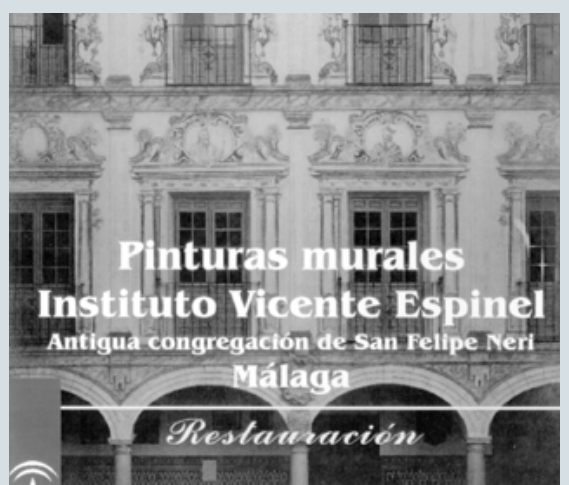

La restauración de las pinturas murales del Instituto Vicente Espinel, Antigua Congregación de San Felipe Neri, en Málaga, fue una obra coordinada por el Departamento de Bienes Muebles de la Dirección General de Bienes Culturales (Consejería de Cultura de la Junta de Andalucía) y realizada por la empresa Ágora, que quedó plasmada en este CD-ROM.

Este CD permite por una parte realizar un recorrido textual, y por otra ofrece la posibilidad de consultar la documentación visual o gráfica producida a raiz de la intervención.

Así, se pueden consultar los gráficos de los tratamientos, las fotografías realizadas previamente a la intervención, en el transcurso de ésta o aquéllas que reflejan el estado final, y los planos de todas las zonas restauradas.

En cuanto al recorrido textual, se inicia con una extensa Introducción en la que se explica el procedimiento seguido. Éste empezó con la redacción de un proyecto de conservación y restauración, con objeto de determinar el estado de conservación del conjun- to y establecer un tratamiento óptimo, para lo cual se analizaron los materiales, el estado de conservación y las patologías sufridas.

Asimismo, en este apartado se especifica el fin último de la intervención, unificar los espacios arquitectónicos del patio a partir de la decoración pictórica, y se justifica la inclusión, junto al estudio técnico, de una memoria histórica que complementa la visión del conjunto. Por último, al final de la introducción aparece la ficha técnica de la restauración realizada.

El siguiente botón nos permite acceder a la Memoria histórica, una muy extensa reseña en la que se hace referencia a la vida de Felipe Neri, la fundación en Italia de la congregación que lleva su nombre, su repercusión en España, y más tarde, la creación de la primera Congregación española de San Felipe Neri. 
A continuación, nos sitúa en el momento histórico que se vivía en la ciudad de Málaga durante el primer tercio del s. XVIII, cuando se disfrutaba de un esplendor económico y una prosperidad que contribuyeron a la proliferación de fundaciones religiosas. La de San Felipe Neri, en concreto, existe en Málaga desde 1739. A partir de ahí se narran todas las fases por las que pasó el edificio y sus múltiples usos. La Memoria histórica finaliza con un apartado dedicado a las pinturas murales (estilo, autores, fechas), a la arquitectura y ornamentación y al programa iconográfico.

Por otro lado, un nuevo botón permite acceder a la información relativa a la Técnica de ejecución de las pinturas murales del patio, con referencias al soporte de las pinturas y de los elementos pétreos, es decir, las columnas y escudos del patio.

El siguiente enlace proporciona acceso a la Analítica, apartado en el que se describe el análisis químico de los materiales y el estudio de la superposición de capas de las pinturas murales realizados en el Instituto Vicente Espinel, como medio precisamente para el conocimiento de la técnica de ejecución. En este sentido, se especifican las técnicas de análisis empleadas (microscopía óptica o electrónica, espectroscopía, cromatografía), los resultados, tanto relativos a la preparación o base de las pinturas como a las capas de color, y las conclusiones.

En cuanto al botón Estado de conservación, hace referencia en primer lugar a la patología sufrida por el conjunto de forma global y las consecuencias en el estado general de conservación en el momento de iniciar la intervención para, a continuación, describir de forma detallada los problemas de las pinturas murales (soporte, base de preparación, película pictórica, estrato superficial e intervenciones anteriores) y de los elementos pétreos.

En último lugar, sin tener en cuenta el botón dedicado al equipo de trabajo, se analizan los Tratamientos a los que se sometió el conjunto artístico. Este apartado comienza con la definición de los criterios aplicados a la intervención, que se realizó con el objetivo fundamental de lograr recuperar tanto el elemento histórico y documental como los valores estéticos.

Posteriormente, se describen las diferentes fases de los tratamientos de las pinturas murales y de los elementos pétreos, desde los trabajos auxiliares previos hasta la redac- ción de la memoria final, pasando por la documentación o la limpieza.

Finalmente, y a modo de orientación a los posibles destinatarios de la información contenida en este CD-ROM, cabe decir que contiene unos textos muy extensos, un tanto excesivos para tratarse de un formato electrónico (con la consiguiente lentitud en la navegación), en los que a veces los caracteres no destacan con claridad del fondo. Es decir, no se trata de un producto ágil en el que se haya hecho hincapié en el diseño. No obstante, como fuente de información, es importante resaltar que se trata de un documento muy completo, por lo que probablemente cumpla mejor su función como herramienta útil para otros profesionales del ámbito de la restauración que como medio de difusión de la labor realizada por una institución a un público más amplio.

Requerimientos técnicos del CD-ROM:

- Tarjeta de sonido

- Pentium 200

- Windows 95

- SVGA

- CD-ROM $\times 20$

- $32 \mathrm{MB}$

María Victoria Madrid Díaz Centro de Documentación, IAPH

\section{Exposiciones en la web sobre pintura mural del medievo francés}

En Internet, podemos encontrar algunos sitios donde se muestra información pormenorizada sobre pinturas murales que han marcado hitos en la historia del arte. Algunos casos concretos como el de Artehistoria.com, alberga información muy detallada sobre grandes genios de la pintura y personajes destacados de la historia, donde se realiza un análisis a todo color, a lo largo de seis galerías de imágenes, sobre los frescos de la Capilla Sixtina, pintados por Miguel Angel Buonarroti en el Cinquecento italiano, con detalles ampliados de cada uno de ellos, así como datos biográficos de su autor y descripción estilística e iconográfica. Todo ello con una muy buena calidad gráfica.
Asimismo, existen otros ejemplos destacados de pintura mural como es el caso de algunos webs que se dedican al análisis del fresco de La Última Cena pintado por Leonardo da Vinci en el Convento de Santa Maria delle Grazie en Milán, donde aparte de su temática, descripción técnica e interpretación, se dedican algunos espacios a analizar y comentar tanto textual como gráficamente, el polémico proceso de restauración que tras 20 años concluyó en 1999.

Pero, tras esta breve introducción, donde no se podía dejar de hacer mención a estos interesantes ejemplos cuyas direcciones daremos al final, el caso que pasamos a anali- zar de un modo más exhaustivo en este número es el de las exposiciones virtuales sobre pintura mural que alberga el Web del Ministerio de la Cultura y la Comunicación de Francia.

El contenido es de sumo interés por su rigor científico, en cuanto a la interpretación, análisis, realización de los recorridos y reproducción fotográfica de las obras.

El acceso a las exposiciones virtuales se encuentra en el índice temático del Web del Ministerio de la Cultura de Francia. Dentro de las mismas, aparecen agrupados por temáticas especializadas distintos museos imaginarios 